\title{
Article \\ The Influence of New and Old Energy Labels on Consumer Judgements and Decisions about Household Appliances
}

\author{
Katarzyna Stasiuk ${ }^{1, *(D)}$ and Dominika Maison ${ }^{2}$
}

1 Institute of Applied Psychology, Jagiellonian University in Krakow, 31-007 Krakow, Poland

2 Department of Psychology, University of Warsaw, 00-927 Warsaw, Poland; dominika.maison@psych.uw.edu.pl

* Correspondence: katarzyna.stasiuk@uj.edu.pl

check for updates

Citation: Stasiuk, K.; Maison, D. The Influence of New and Old Energy Labels on Consumer Judgements and Decisions about Household Appliances. Energies 2022, 15, 1260. https://doi.org/10.3390/en15041260 Academic Editors: Małgorzata Łatuszyńska and Kesra Nermend

Received: 31 December 2021 Accepted: 6 February 2022

Published: 9 February 2022

Publisher's Note: MDPI stays neutral with regard to jurisdictional claims in published maps and institutional affiliations.

Copyright: (C) 2022 by the authors. Licensee MDPI, Basel, Switzerland. This article is an open access article distributed under the terms and conditions of the Creative Commons Attribution (CC BY) license (https:// creativecommons.org/licenses/by/ $4.0 /)$.

\begin{abstract}
Energy efficiency is an increasingly important dimension of household appliances, which is why they are labeled to indicate their energy consumption. In 2020, the European Union countries changed the labeling system from the previous system: ranging from $\mathrm{A}+++$ to $\mathrm{D}$, to the new system: ranging from $A$ to $G$, assuming it would be more transparent for the consumer. The aim of the study was to find out the extent to which consumers are aware of the new labeling system, and the impact that the new labels have (compared to the previous ones) on the perception of household appliances and consumer decision-making. For this purpose, the survey was conducted on a nationwide representative Polish sample $(n=1054)$. The research was partly experimental, where the same appliances were presented with new and previous energy labels. The results showed that currently most people do not identify the new energy classes. Furthermore, products with the new labels are perceived as being less energy efficient in comparison with products with the previous labels, which shows that there is some confusion among consumers in terms of the new energy efficiency labeling system.
\end{abstract}

Keywords: energy labeling system; energy efficiency classes; perception of energy labels; household appliances

\section{Introduction}

Energy-related products, used daily in millions of households around the world, contribute significantly to greenhouse gas emissions and, thus, to negative climate change. Among this group of products, household appliances determine approximately $25 \%$ of total European energy consumption and represent one of the fastest-growing energy loads [1-3]. Being aware of the importance of the problem, the European Union (EU) has for years been implementing initiatives aimed at increasing products' energy efficiency, reducing energy consumption in households, and creating a clear and consumer-friendly labeling system. One of these initiatives is the Energy Label Directive (2010/30/EC adopted in 1992 and recast in 2010), which demands retailers to display the EU energy label whenever household appliances are offered for sale in the EU [4-6]. The new energy labels were introduced in March 2021. The scale from A+++ to D was abandoned and replaced with a scale ranging from $\mathrm{A}$ to $\mathrm{G}$. According to the EU, it should be clear to consumers that $\mathrm{A}$ is the highest rating of efficiency, while $G$ is the lowest, and the scale should also facilitate a deeper consumer understanding and consciousness as to which appliances are the most efficient for the environment [7]. The aims of our research were to find out if consumers are aware of the energy label changes and if they can correctly recognize the meaning of the new energy classes. Moreover, we explored how the new energy labels (compared to the previous ones) affect consumer judgements and decisions: an evaluation of household appliances and of the willingness to buy (WTB) the product. We accomplished these goals by conducting a quantitative survey combined with an experimental design on a representative sample of Polish consumers $(n=1054)$. The introduction of appropriate 
labeling that is clear and comprehensible to the consumer is very important because energy consumption can be reduced by shifting consumer choices towards less energy consuming products. This issue is of particular importance in Poland, where energy consumption is high and growing every year (increasing by 1.4\% per year between 2000 and 2018). The largest energy consumer was the transport sector with a share of $30.2 \%$, while the household sector became the second-largest consumer with a share of $29.0 \%$ in $2018[8,9]$.

\subsection{Energy Labeling and Its Influence on Consumer Judgements and Decisions}

Energy labeling is intended to benefit not only the environment but also manufacturers and consumer issues. It can help manufacturers gain a competitive advantage by producing cost-efficient products and environmentally friendly appliances. For consumers, on the other hand, energy labels are aimed at providing a quick and cognitively effortless way of validating information on the energy consumption of different product alternatives and making better informed purchase decisions [10]. The EU energy label is a comparative label system that rates the energy efficiency of a product in relation to an alphabetical rating scale (the current scale is from $A$ to $G$ ), which covers a large part of the label and is highlighted thanks to a color code from green to red. In addition to the alphabetical scale and a letter indicating the energy class, the label also shows the annual electricity consumption of the appliance in kilowatt hours [2]. Previous studies have shown that consumers attach importance to the efficiency classes of household appliances and are willing to pay more for appliances with a higher energy class than appliances with a lower energy class, even though the energy use difference is negligible $[6,11,12]$. These results can be explained using heuristics - a mental shortcut that allows people to solve problems and make judgments in a fast and efficient manner $[13,14]$. The alphabetical rating scale summarizes energy information in a visible and intuitive way; therefore, consumers may apply decision heuristics based mainly on energy efficiency classes while neglecting more detailed information on energy use (e.g., information on kilowatt consumption) [6,15]. Daniel Kahneman [14] has also referred to this kind of judgement and decision making as WYSIATI: "What You See Is All There Is" — when consumers look at the labels, they fixate on the most visible information, that is, the letter on a colored background, while essentially ignoring other energy efficiency indices [16]. It should be noted that some online stores only display the energy class information of the appliances (not the whole label) on the main display page, and the consumer has to look for more detailed information on energy consumption on the product information sheet, which is located on a subsite. In such a situation, the energy class is an even more important indicator on which consumers base their judgments of a product's energy efficiency.

\subsection{Changes in EU Energy Labeling}

Since the introduction of the energy labels in 1992, the letter scale of the energy classes has been changed twice. From 1992 to 2011, the scale ranged from A to G. However, although the original concept was for only the best products to be A-rated, this highest energy efficiency class has become the standard across many product categories, so much so that up to $90 \%$ of household appliances on the European market were A-rated in the early 21st century. Therefore, the decision was made to introduce three additional top classes $(\mathrm{A}+, \mathrm{A}++, \mathrm{A}+++)$ for the most energy efficient appliances, and the lowest energy classes ranging from $E$ to $G$ to be removed from the labels of such appliances in order to maintain seven energy classes on the label (with the least energy-efficient class marked as D). While this updated $2011 \mathrm{EU}$ A+++ to D energy labeling scheme was thought to have increased the market share of highest-rated appliances, in 2017, the EU decided to revert to the earlier $A$ to $G$ classification. It was recognized that $A$ to $A+++$ labels may result in incorrect appliance evaluations because consumers may have erroneously interpreted an $\mathrm{A}$ or A+ label as a top energy efficiency rating. The current A to $G$ version of the energy label has been on the market since March 2021. It was designed so that very few appliances will initially be able to achieve an " $\mathrm{A}$ " rating, leaving space for more efficient products to be 
introduced in the future. Therefore, the most energy efficient appliances that are currently available on the market have $\mathrm{B}$ or $\mathrm{C}$ energy classes, which correspond to the previous A+++ class $[7,17]$. The introduction of these changes was accompanied by information campaigns explaining to consumers why and what has changed in the new energy labeling scheme (See e.g., https:/ / www.gov.pl/web/klimat/nowe-etykiety-energetyczne (accessed on 25 November 2021) for the Polish governmental campaign).

The main aim of the research presented in this paper is to analyze the effect of the rescaled A to $G$ labeling system on consumer preferences for household appliances compared to the A+++ to D scale. Based on a study by Heinzle and Wustenhagen [9], after the first scale change (from the "A to G" scale to the "A+++ to D" scale), an improved effectiveness of the label with the restored A to $G$ scale can be expected. Their results showed that the impact of the A to G scale on consumers' decisions was much stronger than the $\mathrm{A}+++$ to $\mathrm{D}$ scale, and consumers were more willing to pay a higher premium for the highest classes of the A to G scale than for the classes of the A-plus scale. However, on the other hand, it should be kept in mind that the $\mathrm{A}+++$ to $\mathrm{D}$ scale has been on the market for ten years. Hence, consumers have already had time to become familiar and accustomed to this scale and, therefore, are now more capable of differentiating the ratings for products labeled A+++ and A+ or A than when Heinzle and Wustenhagen conducted their study. Furthermore, because there have been mainly $\mathrm{A}+++$ to A rated products on the market for the past ten years, this may have led to the fluency effect in consumer judgements as a consequence of repeated exposure to the stimulus. The fluency effect is the ease with which information can be processed, due to a previous encounter, and may serve as a basis for preferences (see e.g., $[18,19])$. Applying the fluency effect to the household appliance labeling system, it can be assumed that the energy classes that consumers have encountered in the market for the past ten years are easier for them to process than the labels with the new classes. They do not have to expend the cognitive effort to figure out what $\mathrm{A}+++$ or A+ rating means, but they do have to put in more effort to grasp what level of energy consumption the new B or D class means. This processing fluency may be reflected in the preferences for products with the outgoing classes.

Moreover, it is possible that consumers use two overarching categories of "better products", and "worse products". A+++ to A are the better products between which the consumer is most likely to choose, and anything below A is a worse product, less likely to be considered. By using an experimental design, we wanted to find out which of these assumptions would turn out to be correct. In addition, we conducted a survey (based on the same representative sample of respondents) to obtain additional information on the extent to which consumers are aware of the label change and what percentage of the population is able to correctly read the meaning of the new labels.

Our study extends the existing literature on energy label perceptions and their influence on consumer judgements and decisions. While there have been previous experiments in this area, they mainly focused on the perceptions of the A+++ to D energy class system (applicable until 2021) [6,16] or compared both labeling systems, but these studies were carried out before the official rollout of the new A to G system (e.g., a study conducted in 2018 by Faure, Guetlein \& Schleich [17]). As far as we know, there has not yet been much research since products with the new labeling system appeared on the market showing how the labeling systems influence consumer judgements and decisions. In addition, earlier studies often showed consumers only the full energy labels of products (sometimes with additional information about them, such as their price, guarantee, and capacity) $[6,10,17]$. In order to increase the ecological relevance of the experiment, we decided to precisely map the website of one of the large European home appliance stores (Media Markt) and the information about the household appliance that appears after using. On its main page, it presents only the energy class of the product (without information on energy consumption, which appears only after entering the product page). These may determine that the consumer will (or will not) include the product in his or her basket of alternatives and decide (or not) to look for more information about it. Finally, in many previous studies 
respondents were only asked about their declaration of choice of appliances with a specific energy label, whereas we were interested not only in the declaration of choice but also in consumers' perception of the different attributes of the products (their quality, environmental performance, energy savings, and price adequacy) depending on the different information about the energy classes that was displayed.

\section{Method}

\subsection{Participants}

The research sample consisted of 1054 respondents and was representative for the Polish population. The survey was run online in October 2021 by the Ariadna Nationwide Research Panel, a Polish counterpart of mTurk - a company specialized in the polling of large samples for the purpose of research. The panel enables the random selection of a sample from among 300,000 registered and verified Polish respondents. The respondents received credit points for their participation in the survey, which they could later exchange for gifts. A random quota sampling method was used, based on sex (2 subgroups), age (5 subgroups), place of residence (5 subgroups), and education (6 subgroups). Each demographic criterion was controlled to be representative of the Polish general population-giving a total of 50 weighted cells. Weights were calculated based on these four demographic criteria and the participants were drawn randomly from the cells to fit the demographic quotas.

The sample was 52\% women and 58\% men; $10 \%$ were aged $18-24 ; 21 \%$ between 25-34; 36\% were aged between 35-54; 33\% were aged 55 and more; $13 \%$ had primary or vocational education; $44 \%$ had secondary or postsecondary education; and $43 \%$ had a bachelor's degree. Moreover, $47 \%$ of the participants lived in a rural/small town (under 20k residents, $22 \%$ in a medium town (20,000-99,000 residents), and $31 \%$ in a city or large city $(100,000-$ over 500,000 residents), which represents the structure of the Polish population.

\subsection{Materials and Design}

The questionnaire was presented online on the Ariadna survey platform. The questionnaire consisted of single choice items, which required an average of $10 \mathrm{~min}$. to be completed and was divided into three sections: (a) experimental part: product presentation and evaluation thereof; (b) awareness and understanding of previous and new energy efficiency labeling; and (c) demographic data, including age, gender, education, and place of residence. In the experimental part of the study, the participants were presented with an original print screen of a Media Markt store (European home appliance store) website showing an LG refrigerator, which was chosen as an example of a household appliance (see Appendix A). The participants were randomly assigned to one of the four conditions in a between-subject design $(2 \times 2)$, with the type of energy efficiency label (previous vs. new) and the energy efficiency level of the refrigerator (lower vs. higher) as the independent variables. With this scheme, all the respondents were presented with the same refrigerator with different energy efficiency labels depending on the condition: (1) A+++ label-previous label system, higher energy efficiency; (2) A label-previous label system, lower energy efficiency; (3) C label—new label system, higher energy efficiency; (4) F label—new label system, lower energy efficiency. As we wrote before, it is important to note that the Media Markt website only gives the energy class without any information on the annual energy consumption. This information appears only after opening the detailed information about a given appliance. After presenting the screen of the website, the participants were asked several questions about their perception of the refrigerator. In the first question, they were asked about their overall evaluation of the refrigerator on a 7-point scale from -3 definitely negative to 3 definitely positive. In the second question, the participants were asked to rate how well the six given attributes (energy saving, economical in use, good quality, reliable, environmentally friendly, and ecological) fit the refrigerator using a 7-point scale from -3 does not fit at all to 3 definitely fits. The scores for these attributes were then averaged and reduced to three dimensions used in the analyses: Energy efficiency (energy saving and economical in use), Eco-friendliness (environmentally friendly and ecological), and Quality (good 
quality, reliable). Next, the participants were asked to evaluate how adequate the price of the refrigerator is to its quality, using a 7-point scale from -3 the price is too high in relation to quality to 3 the price is too low in relation to quality. The last section was about the willingness to buy the refrigerator (Imagine that you have been wanting to buy a refrigerator for a long time. How likely is it that you would consider the refrigerator you just saw?) with a 7-point scale from -3 definitely unlikely to 3 definitely likely.

After the experimental part, the participants were asked several questions related to their awareness of household appliance energy efficiency labeling. In the first question of this part, they were asked if they pay attention to energy efficiency labeling, with the possible answers being yes or no. In in the second question, they were asked what a $\mathrm{C}$ energy efficiency label means, with the possible answers being high energy efficiency, medium energy efficiency, low energy efficiency, and I don't know. In the third and fourth question, the participants were presented with the previous and new energy efficiency labels, respectively, and asked if they knew them, with the possible answers being yes or no.

\subsection{Ethical Considerations}

The study protocol was reviewed and approved by the Ethics Committee of the Institute of Applied Psychology, Jagiellonian University in Krakow (Poland). The questionnaire collected no identifying personal data from the participants. Informed consent was obtained from all the subjects involved in the study.

\subsection{Data Analysis}

The IBM SPSS Statistics (SPSS) software version 26 was used to analyze the data.

\section{Results}

\subsection{Awareness of Energy Efficiency Classes}

In the first stage of the analyses, we counted the scores for the questions on the awareness of the energy efficiency labels for household appliances (Note that, not wanting to sensitize the subjects to the topic of the study, during the survey, these questions were asked only after the experimental part). The majority of respondents (88\%) declared that they pay attention to the energy label (vs. 12\% admitting not paying attention). Moreover, the majority of respondents also declared that they know the previous and new energy class labels, slightly more declared this in the case of the previous labels $-80 \%$, as compared to the new labels-74\% (Figure 1). However, when we directly asked about the meaning of the new classes (using the new C class as an example), $40 \%$ of the respondents admitted that they did not know it, and 19\% read it mistakenly, indicating that the label indicates low energy efficiency. When we looked at the responses separately for those who said they knew or did not know the meaning of the new labels, we observed differences between the groups. Among those who said that they were familiar with the new labels, 31\% stated that they did not know what the new C class label meant, and 20\% said the label indicated a low energy efficiency. Among those who claimed to be unfamiliar with the new labels, $64 \%$ confirmed that they did not understand the meaning of the C class label (see Figure 2).

\subsection{The Influence of Energy Efficiency Labeling on Household Appliance Evaluations and Consumer Willingness to Buy It-Experimental Part}

When analyzing the results of the experimental part, we decided to conduct two separate analyses. One analysis for people who declared that they pay attention to energy labels and that they know the new energy labels $(n=734)$, and the second analysis for people who said that they do not pay attention to these labels $(n=131)$ (Since there were only 131 of such people, we did not divide them further into those who had declared that they knew the new energy efficiency labels and those who had not).

By carrying out the analysis in two groups, we wanted to check whether the decisions of consumers who declare that they are aware of energy class labels are really guided by these labels when evaluating household appliances and considering their purchase and 
whether these labels really do not influence the evaluations and decisions of those who declared that they do not pay attention to them.

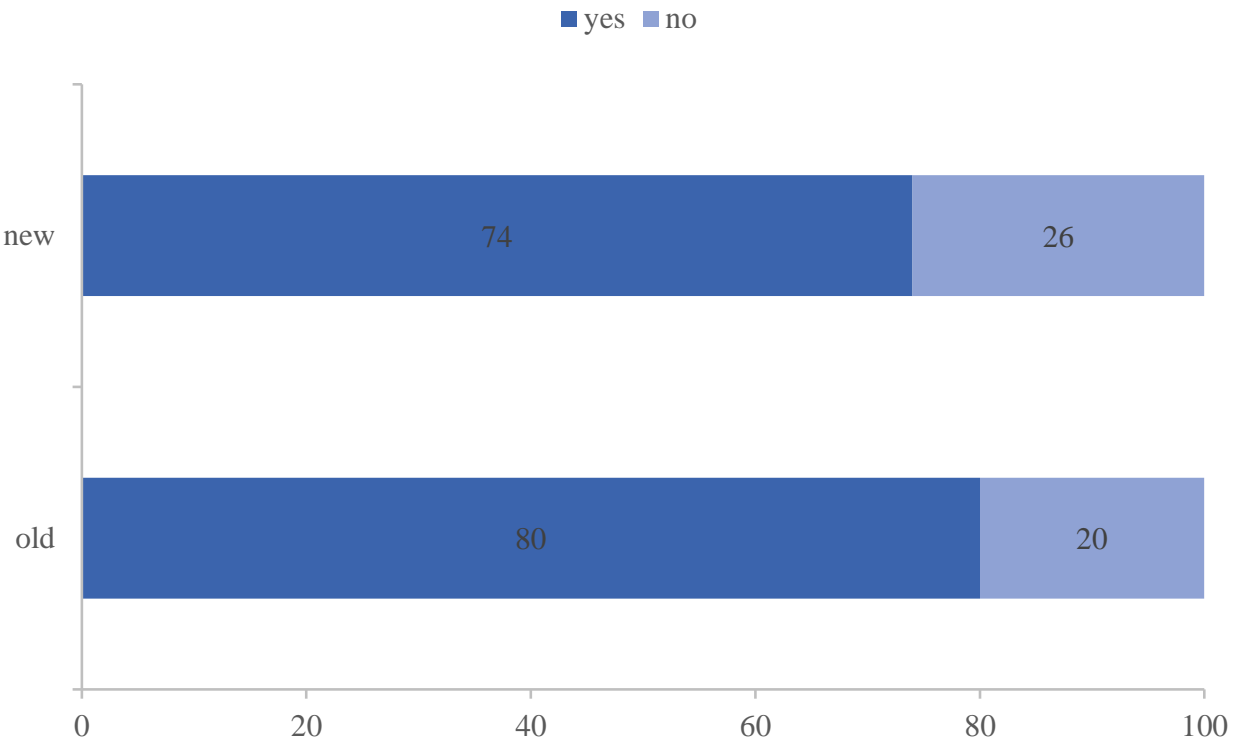

Figure 1. Knowledge of the energy efficiency classes, $n=1054$. Note: When answering a question, the correct label for the question (new or old) was displayed on the screen.

- high energy efficiency of the appliance medium energy efficiency of the appliance

- low energy efficiency of the appliance

I don't know

does not know the new labels

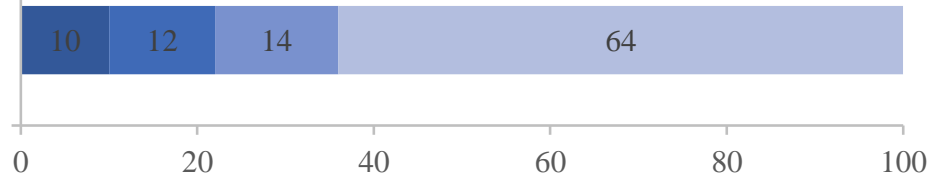

Figure 2. Understanding the meaning of the new $C$ class energy label in two groups: those who declare knowing $(n=779)$ and not knowing $(n=275)$ the new label (total: $n=1054)$.

3.3. The Influence of the New vs. Old Energy Efficiency Labels-Analysis for Consumers Declaring Paying Attention to the Labels and Knowing the New Energy Efficiency Classes

In order to check the influence of new vs. previous energy efficiency labels informing about a lower vs. higher energy efficiency, a $2 \times 2$ analysis of variance was performed (type of label: current/previous by energy class: lower/higher energy). The analysis yielded the significant main effects of the type of label (previous vs. new) for the following dependent variables: energy efficiency, eco-friendliness, and price adequacy. The type of label main effect for quality perception and for willingness to buy the product were close to significancy, and the overall evaluation of the product was not significant (Table 1). The participants evaluated the refrigerator with the previous energy labels $(\mathrm{A}+++$ and $\mathrm{A})$ as significantly more energy efficient $(\mathrm{M}=1.7 ; \mathrm{SD}=1.05)$ than the refrigerators with the new energy labels ( $\mathrm{F}$ and $\mathrm{C}, \mathrm{M}=1.3 ; \mathrm{SD}=1.4)$, more eco-friendly $(\mathrm{M}=1.5 ; \mathrm{SD}=1.06$ vs. $\mathrm{M}=1.3$; $\mathrm{SD}=1.1)$, and of a slightly higher quality $(\mathrm{M}=1.5 ; \mathrm{SD}=1.01 \mathrm{vs.} \mathrm{M}=1.4 ; \mathrm{SD}=1.1)$, see Figure 3 . They also tended to evaluate the price of the prior-system labeled refrigerators as slightly overestimated and the price of the current -system labeled refrigerators as 
slightly underestimated $(\mathrm{M}=0.1, \mathrm{SD}=1.3$ vs. $\mathrm{M}=-0.05, \mathrm{SD}=1.4)$ and declared a higher willingness to buy the new-system labeled refrigerators than the prior-system labeled refrigerators $(\mathrm{M}=0.7, \mathrm{SD}=1.6$ vs. $\mathrm{M}=0.4, \mathrm{SD}=1.7)$, see Figure 4 .

Table 1. The main effects for the type of label.

\begin{tabular}{llll}
\hline & F & $p$ & $\dot{\eta}$ \\
\hline Energy efficiency & $F_{(1,730)}=15.44$ & $p<0.01$ & $\dot{\eta}=0.02$ \\
\hline Eco-friendliness & $F_{(1,730)}$ & $p=0.003$ & $\dot{\eta}=0.01$ \\
\hline Quality & $F_{(1,730)}=3.94$ & $p=.060$ & $\dot{\eta}=0.005$ \\
\hline Overall evaluation & $F_{(1,730)}=0.45$ & $p=0.502$ & $\dot{\eta}=0.001$ \\
\hline Price adequacy & $F_{(1,730)}=3.94$ & $p=0.048$ & $\dot{\eta}=0.005$ \\
\hline Willingnes to buy (WTB) & $F_{(1,730)}=3.94$ & $p=0.053$ & $\dot{\eta}=0.005$ \\
\hline
\end{tabular}

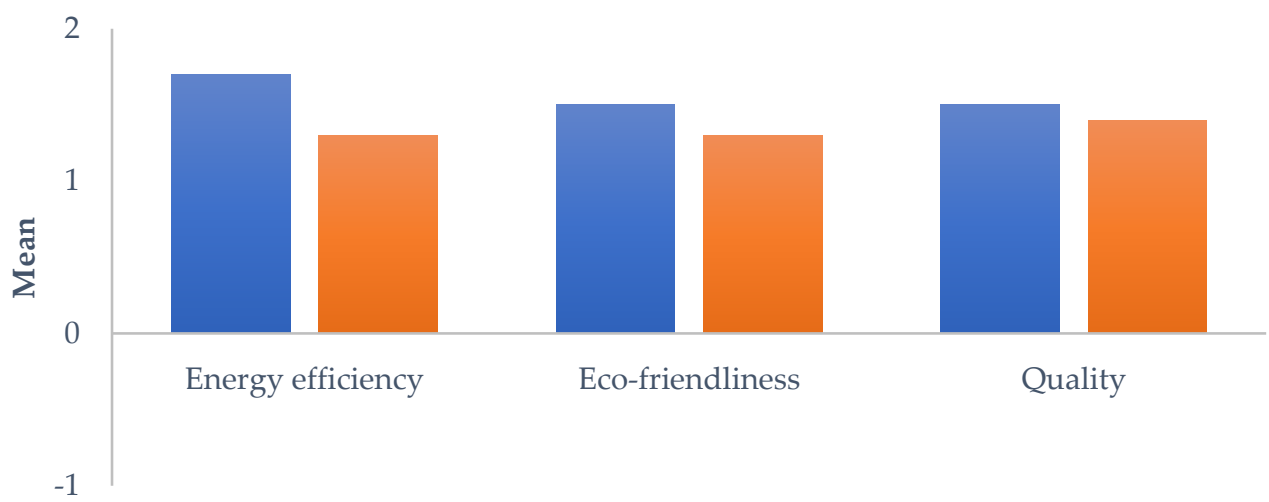

Figure 3. Evaluation of refrigerator attributes - for the product with the previous $(n=345)$ and the new $(n=389)$ energy efficiency labels (total $n=734)$.

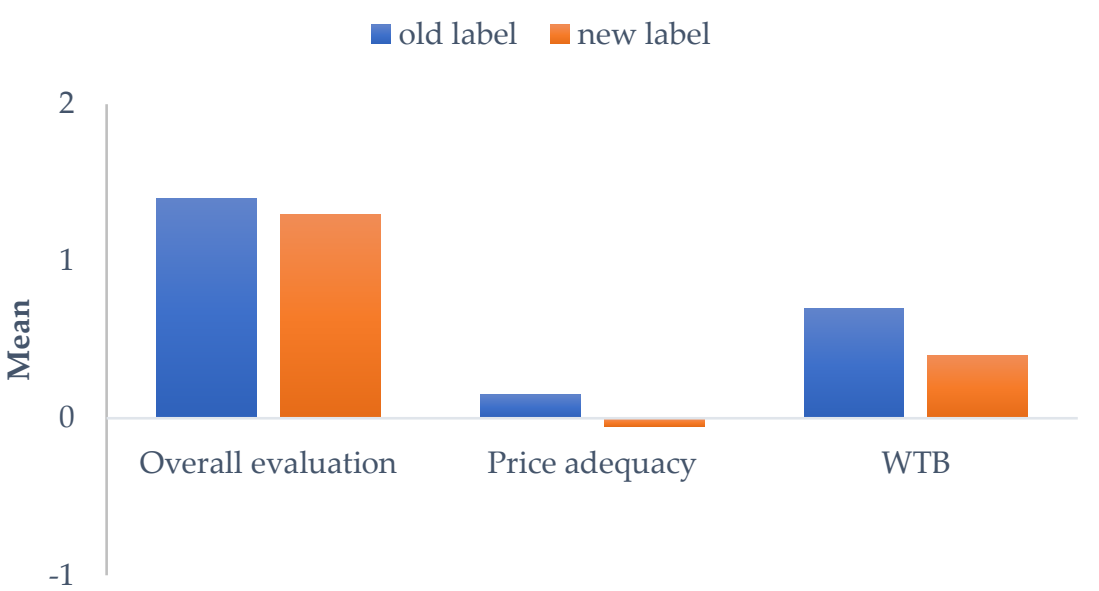

Figure 4. The overall refrigerator evaluation, price adequacy evaluation, and willingness to buy (WTB) for the product with the previous $(n=345)$ and the new $(n=389)$ energy efficiency labels (total $n=734$ ).

The analyses also revealed the main effects of the energy class for the following dependent variables: energy efficiency, eco-friendliness, quality, and overall evaluation. The main effect for price adequacy and willingness to buy were not significant; see Table 2 . The overall evaluation of the refrigerators with a higher energy class together was significantly 
higher $(\mathrm{M}=1.5 ; \mathrm{SD}=1.2)$ than the evaluation of refrigerators with a lower energy class $(\mathrm{M}=1.29 ; \mathrm{SD}=1.2)$, regardless of whether the labels were in the old or the new labeling system. The higher energy class refrigerators (independently of whether they had the previous or the new label) were also perceived as being more energy efficient $(\mathrm{M}=1.6$; $\mathrm{SD}=1.1)$ than the lower energy class refrigerators $(\mathrm{M}=1.3 ; \mathrm{SD}=1.2)$, more Eco-friendly $(\mathrm{M}=1.4 ; \mathrm{SD}=1.1$ vs. $\mathrm{M}=1.2 ; \mathrm{SD}=1.1)$ and of a higher quality $(\mathrm{M}=1.4 ; \mathrm{SD}=1.07$ vs. $\mathrm{M}=1.3 ; \mathrm{SD}=1.09$ ); see Figures 5 and 6.

The interaction effects of the type of label and the energy class were not significant.

Table 2. The main effects for energy Class.

\begin{tabular}{llll}
\hline & F & $p$ & $\dot{\eta}$ \\
\hline Energy efficiency & $F_{(1,730)}=10.02$ & $p=0.002$ & $\dot{\eta}=0.01$ \\
\hline Eco-friendliness & $F_{(1,730)}=4.38$ & $p=0.037$ & $\dot{\eta}=0.006$ \\
\hline Quality & $F_{(1,730)}=4.02$ & $p=0.045$ & $\dot{\eta}=0.005$ \\
\hline Overall evaluation & $F_{(1,730)}=5.46$ & $p=0.020$ & $\dot{\eta}=0.007$ \\
\hline Price adequacy & $F_{(1,730)}=0.768$ & $p=0.381$ & $\dot{\eta}=0.001$ \\
\hline Willingnes to buy (WTB) & $F_{(1,730)}=2.38$ & $p=0.123$ & $\dot{\eta}=0.003$ \\
\hline
\end{tabular}

uhigher class lower class

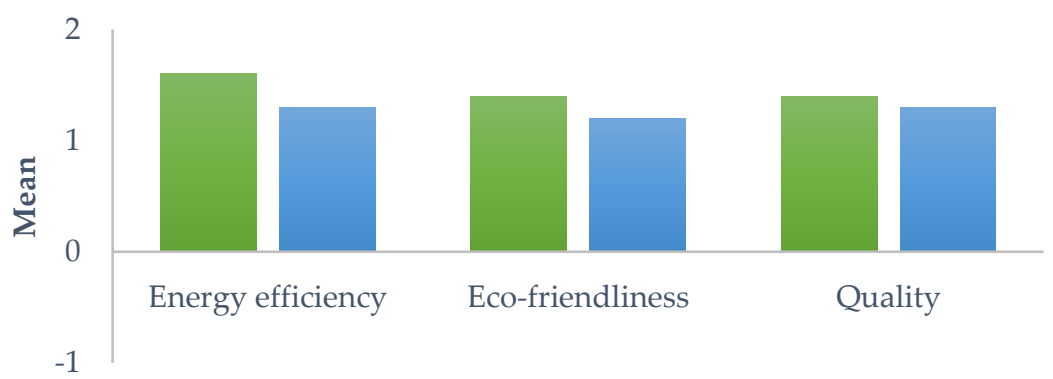

Figure 5. Evaluation of attributes for refrigerators with a higher and a lower energy class $(n=734)$.

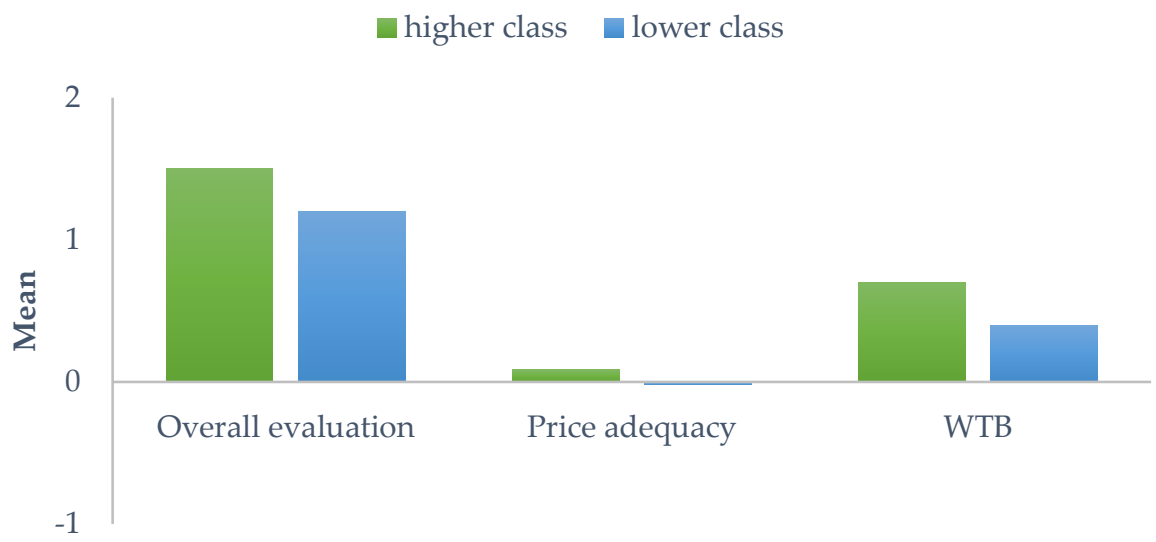

Figure 6. The overall refrigerator evaluation, the price adequacy evaluation, and the willingness to buy for the refrigerators with a higher and a lower energy class $(n=734)$.

\subsection{The Influence of the New vs. Old Energy Efficiency Labels-An Analysis for Consumers} Declaring Paying No Attention to Energy Efficiency Labels

An analysis of the results for the group of respondents who declared that they do not pay attention to energy labels $(n=131)$ showed that the information about the energy class 
indeed did not influence their judgments and decisions regarding the presented refrigerator. $2 \times 2$ ANOVA (type of label: old/new by energy class: lower/higher) did not reveal any main effects nor interaction effects of the type of label and the energy class for all the tested dimensions: overall evaluation, energy efficiency, eco-friendliness, quality, price adequacy, as well as WTB.

\section{Discussion}

In accordance with new European Union regulations, manufacturers of household appliances must introduce the new energy class labels for their products from 2021. The existing scale from $\mathrm{A}+++$ to $\mathrm{D}$ has been changed to a scale ranging from $\mathrm{A}$ to $\mathrm{G}$. The new scale is intended to be more straightforward for consumers and, thus, to better help them cut their energy bills and carbon footprint. The most energy efficient products currently on the market will now typically be labeled B or C. The highest class A is temporarily to be left empty, leaving space for more efficient products to be included in the future. The purpose of our study was first to see if consumers are familiar with the new energy class system and whether they correctly identify the labels and also to see how this new system affects product judgments and purchase decisions. The vast majority of consumers declared that they pay attention to the energy class labels of home appliances, which is consistent with the results of previous studies (see [11,20,21]. Most of the respondents also declared that they were familiar with both the old and the new energy class labeling system. However, when we asked them what level of appliance energy efficiency class C stands for, about half of the respondents (who had previously declared that they pay attention to appliance energy efficiency) did not know or incorrectly indicated that it denotes a low level of product energy efficiency. These results are in line with the broad literature on judgment and decision-making (including in the area of consumer behavior) that differentiates between the concepts of objective knowledge and subjective knowledge. Objective knowledge is an individual stores in their long-term memory; in turn, subjective knowledge refers to the self-perception of one's own knowledge. While it is reasonable to assume that people's perception of their subjective knowledge strongly reflects their actual knowledge in afield, much research has shown that people tend to overestimate it even in contexts in which they are not educated or professionally engaged [22]. Our results have revealed that consumers may also tend to overestimate their knowledge regarding energy labels, which is important information that should be taken into account in further studies (checking not only the subjective knowledge but also the actual level of knowledge).

The results of the experimental part also demonstrate that the new labels (at least for now) may be confusing for consumers and less beneficial for manufacturers. Refrigerators marked with the new labels (C or F) were perceived as less energy efficient and less environmentally friendly than the same refrigerators but with the previous labels $(\mathrm{A}+++$ or A). Moreover, the price of a refrigerator marked with a new label was perceived as being overestimated, and the product was less likely to be considered as suitable for purchase than a product marked with the previous corresponding label.

The results of our study mean that the new energy class scale is not yet clear for many consumers (even for consumers who claim to be familiar with this new scale). Over the last few years, products with energy classes ranging from A to A+++ have been predominantly present on the market. This may have led consumers to treat them as some obvious standard of energy efficiency that (in their view) products with grades lower than A do not meet. Moreover, it is likely that many consumers are unaware that, under the new labeling system, the A class is to be left blank for the time being, waiting for new technologies to emerge, and that products with B or C classes may have the same (or even lower) energy consumption as products with the $\mathrm{A}+++$ label in the previous system.

Problems in understanding the meaning of the new energy classes may also be a result of the situation that consumers face both in stationary and online household appliance stores. Firstly, the new energy efficiency class is being gradually introduced for different categories of household appliances-products such as fridges and dishwashers have been 
marked with it since March 2021, while air conditioners, tumble dryers, vacuum cleaners, and water heaters will start to be marked with it in 2022. Secondly, the period from 1 March to 31 November is a transition period during which refrigerators and dishwashers can be sold with both the new and the old energy label. This means that, in recent months, consumers will have seen both appliances with the old and the new labels in stores. It must be noticed that most household appliances with the previous energy efficiency labels are rated no lower than $\mathrm{A}$, which can create a contrast effect when consumers see appliances with the old and the new labels. The contrast effect is a cognitive tendency that manifests itself in the perception of an intensified or increased difference between two stimuli or objects when they are juxtaposed or when one immediately follows the other [23,24]. According to this effect, an appliance labeled as class C, for example, may be rated lower when a consumer sees it next to an appliance labeled as class $\mathrm{A}$ or $\mathrm{A}+++$.

Finally, despite the fact that the EU intended the new energy class A to be temporarily empty, we found washing machines labeled with class A in the new scale in well-known household appliance stores (Media Expert). This again may lead to the B- or C-labeled appliances displayed next to them being rated lower by consumers (even if their energy efficiency level is the same).

\section{Conclusions}

The results of our survey show that despite the extensive information provided and the education campaign carried out over the past year to familiarize consumers with the new energy class labeling rules, many consumers are still unable to interpret them correctly. This may (for now, at least) be to the detriment of manufacturers of low energy consumption appliances currently labeled as B or C classes, which are evaluated in the context of products with the previous energy efficiency labeling, leading to lower ratings of their energy efficiency. These results have important managerial implications. They indicate that it may well be useful to communicate the change of energy labeling not only on the Internet on dedicated websites (which need to be specifically researched) but also, for example, at points of sale. It would also be advisable to ensure that the new energy class is, for a certain period of time, accompanied by information on the previous class (as some stores do).

This study, while providing important information, has some limitations. First, in the experimental part, the respondents were asked to evaluate only one type of home appliance-refrigerators. An interesting question is how the new energy efficiency labels affect the perception of other appliances like, for instance, appliances where consumers pay less attention to energy consumption (such as hair dryers). Secondly, it is interesting to study how labels influence consumer judgements depending on the purchase channel: online and offline. Our study focused exclusively on online stores where products in store browsers are often presented with the energy class alone (without any information on the annual energy consumption, which appears only after opening the detailed information about a given appliance). In stationary stores, however, consumers see the products with the full energy efficiency labels affixed (including information about the annual energy consumption). Therefore, it would be interesting to replicate this research in a situation of non-internet choices.

Author Contributions: Conceptualization, K.S. and D.M.; methodology, K.S. and D.M.; formal analysis, K.S.; writing — original draft preparation, K.S. and D.M.; writing-review and editing, K.S. and D.M. All authors have read and agreed to the published version of the manuscript.

Funding: This research was supported by the Faculty of Psychology, University of Warsaw, from the funds awarded by the Ministry of Science and Higher Education in the form of a subsidy for the maintenance and development of research potential in 2021 (501-D125-01-1250000 zlec. 5011000250). The publication was funded by the Priority Research Area Society of the Future under the program "Excellence Initiative-Research University" at Jagiellonian University in Krakow. 
Institutional Review Board Statement: The study was conducted according to the guidelines of the Declaration of Helsinki and approved by the Ethics Committee of Institute of Applied Psychology, Jagiellonian University in Krakow (10/21).

Informed Consent Statement: Informed consent was obtained from all subjects involved in the study.

Data Availability Statement: The data presented in the study are openly available in OSF repository. This data can be found here: https:/ / osf.io/g4j52/?view_only=b59206b79e6b446ca7a502017f70ec36 (accessed on 30 December 2021).

Conflicts of Interest: The authors declare no conflict of interest.

\section{Appendix A. The Materials Used in the Experimental Part of the Study}

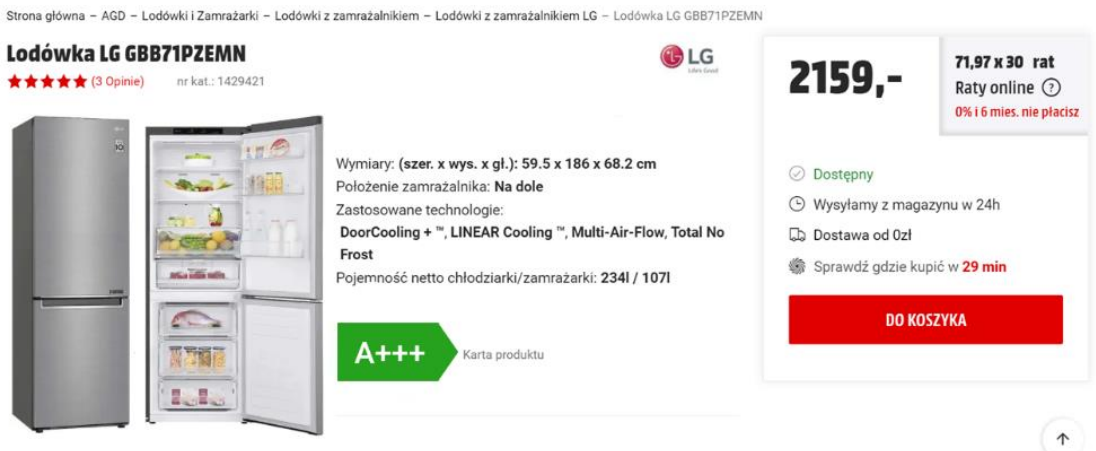

Figure A1. Higher class and previous system label for refrigerator.

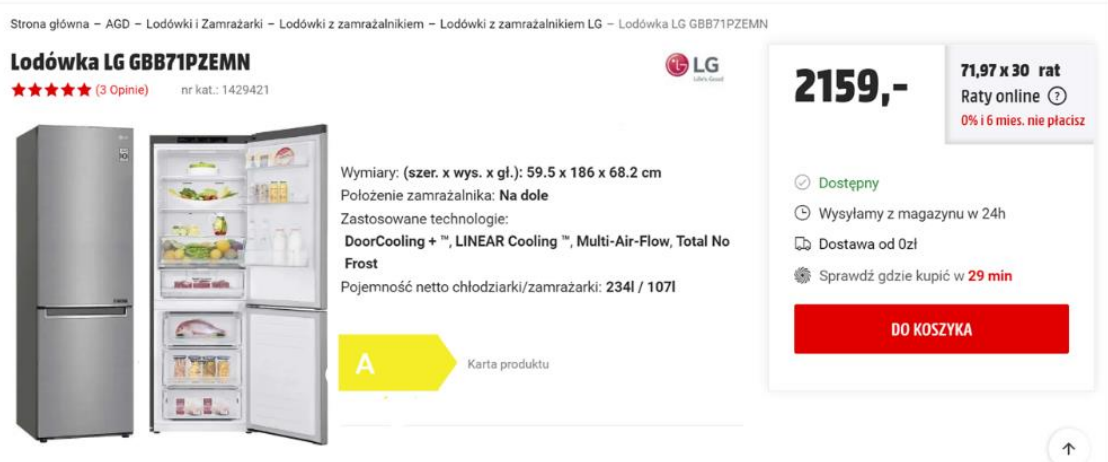

Figure A2. Lower class and previous system label for refrigerator.

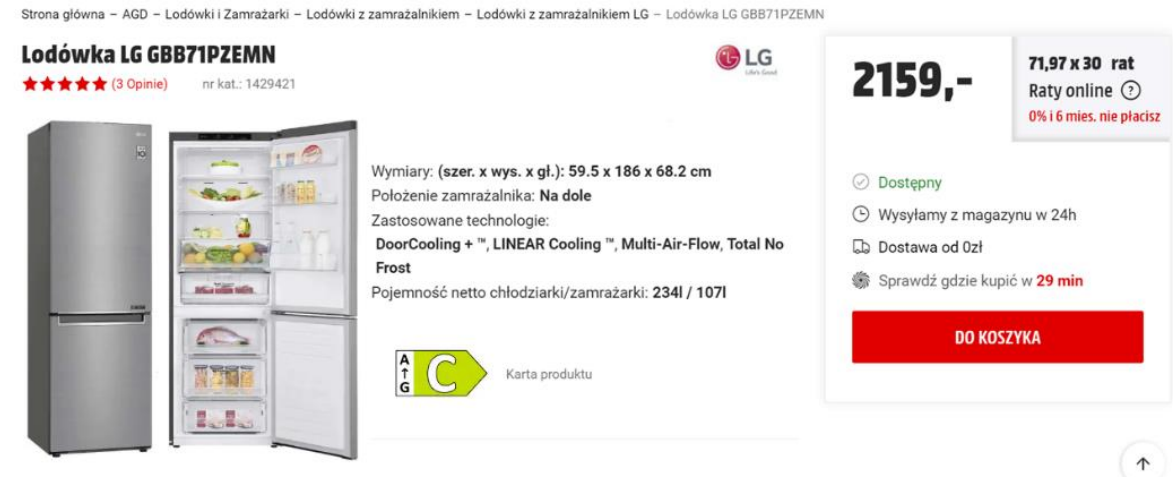

Figure A3. Higher class and current system label for refrigerator. 

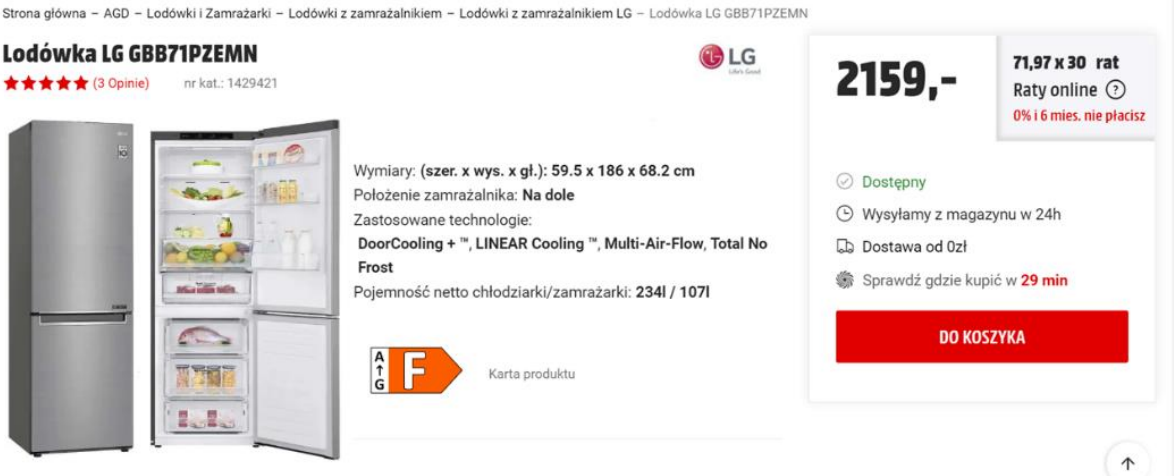

Figure A4. Lower class and current system label for refrigerator.

\section{References}

1. Behbahanifard, H.; Sadoughi, A. Chapter $1 \pm$ Climate Change and Kyoto Protocol: An Overview. J. Electr. Eng. Technol. 2016, 11, 878-888. [CrossRef]

2. Russo, A.C.; Rossi, M.; Germani, M.; Favi, C. Energy label directive: Current limitations and guidelines for the improvement. Procedia CIRP 2018, 69, 674-679. [CrossRef]

3. Meehan, P.; McArdle, C.; Daniels, S. An Efficient, Scalable Time-Frequency Method for Tracking Energy Usage of Domestic Appliances Using a Two-Step Classification Algorithm. Energies 2014, 7, 7041-7066. [CrossRef]

4. Hueppe, C.; Geppert, J.; Moenninghoff-Juessen, J.; Wolff, J.; Stamminger, R.; Paul, A.; Elsner, A.; Vrabec, J.; Wagner, H.; Hoelscher, H.; et al. Investigating the real life energy consumption of refrigeration appliances in Germany: Are present policies sufficient? Energy Policy 2021, 155, 112275. [CrossRef]

5. Thøgersen, J. Psychological Determinants of Paying Attention to Eco-Labels in Purchase Decisions: Model Development and Multinational Validation. J. Consum. Policy 2000, 23, 285-313. [CrossRef]

6. Andor, M.; Gerster, A.; Sommer, S. Consumer inattention, heuristic thinking and the role of energy labels. In Ruhr Economic Papers; RWI-Leibniz-Institut für Wirtschaftsforschung, Ruhr-University Bochum, TU Dortmund University, University of Duisburg-Essen: Essen, Germany, 2017; Volume 671.

7. European Union. Commission delegated regulation (EU) 2019/2016 of 11 March 2019 supplementing regulation (EU) 2017/1369 of the European parliament and of the council with regard to energy labelling of refrigerating appliances and repealing commission delegated regulation (EU) No 1060/2010 (text with EEA relevance). Off. J. L 2019, 315, 102-133. Available online: http:/ / data.europa.eu/eli/reg_del/2019/2016/oj (accessed on 15 December 2021).

8. Zielińska-Sitkiewicz, M.; Chrzanowska, M.; Furmańczyk, K.; Paczutkowski, K. Analysis of Electricity Consumption in Poland Using Prediction Models and Neural Networks. Energies 2021, 14, 6619. [CrossRef]

9. Odysse-Mure. Poland Energy Efficiency Summary. Available online: https:/ /www.odyssee-mure.eu/publications/efficiencytrends-policies-profiles / poland-polish.html (accessed on 20 December 2021).

10. Heinzle, S.L.; Wüstenhagen, R. Dynamic adjustment of eco-labeling schemes and consumer choice-the revision of the EU energy label as a missed opportunity? Bus. Strat. Environ. 2012, 21, 60-70. [CrossRef]

11. Sammer, K.; Wüstenhagen, R. The influence of eco-labelling on consumer behaviour-Results of a discrete choice analysis for washing machines. Bus. Strategy Environ. 2006, 15, 185-199. [CrossRef]

12. Shen, J.; Saijo, T. Does an energy efficiency label alter consumers' purchasing decisions? A latent class approach based on a stated choice experiment in Shanghai. J. Environ. Manag. 2009, 90, 3561-3573. [CrossRef]

13. Tversky, A.; Kahneman, D. Judgment under uncertainty: Heuristics and biases. Science 1974, 185, 1124-1131. [CrossRef]

14. Kahneman, D. Thinking, Fast and Slow; Farrar, Straus and Giroux: New York, NY, USA, 2011.

15. Andor, M.A.; Gerster, A.; Götte, L. How effective is the European Union energy label? Evidence from a real-stakes experiment. Environ. Res. Lett. 2019, 14, 044001. [CrossRef]

16. Davis, L.W.; Metcalf, G.E. Does better information lead to better choices? Evidence from energy-efficiency labels. J. Assoc. Environ. Resour. Econ. 2016, 3, 589-625. [CrossRef]

17. Faure, C.; Guetlein, M.C.; Schleich, J. Effects of rescaling the EU energy label on household preferences for top-rated appliances. Energy Policy 2021, 156, 112439. [CrossRef]

18. Zajonc, R.B. Feeling and thinking: Preferences need no inferences. Am. Psychol. 1980, 35, 151-175. [CrossRef]

19. Whittlesea, B.W.; Price, J.R. Implicit/explicit memory versus analytic/nonanalytic processing: Rethinking the mere exposure effect. Mem. Cogn. 2001, 29, 234-246. [CrossRef]

20. Si-Dai, G.; Cheng-Peng, L.; Hang, L.; Ning, Z. influence mechanism of energy efficiency label on consumers' purchasing behavior of energy-saving household appliances. Front. Psychol. 2021, 12, 711854. [CrossRef] 
21. Tan, L.P.; Johnstone, M.L.; Yang, L. Barriers to green consumption behaviors: The roles of consumers' green perceptions. Australas. Mark. J. 2016, 24, 288-299. [CrossRef]

22. Alba, J.W.; Hutchinson, J.W. Knowledge calibration: What consumers know and what they think they know. J. Consum. Res. 2000, 27, 123-156. [CrossRef]

23. Meyers-Levy, J.; Sternthal, B. A two-factor explanation of assimilation and contrast effects. J. Mark. Res. 1993, 30, 359-368. [CrossRef]

24. Lynch, J.G., Jr.; Chakravarti, D.; Mitra, A. Contrast effects in consumer judgments: Changes in mental representations or in the anchoring of rating scales? J. Consum. Res. 1991, 18, 284-297. [CrossRef] 